\title{
Correspondence
}

\section{A call to commission more women writers}

We have analysed the gender distribution of authors of News \& Views articles in Nature and of Perspectives in Science for 2010 and 2011. Our numbers indicate that both journal sections underrepresent women scientists.

We divided the articles into three broad subject categories: biological and chemical sciences (which includes medical sciences); physical sciences; and Earth and environmental sciences. We compared the proportion of women authors with the proportion of women scientists employed in 2006 in the United States in science and engineering in each of the three categories (see go.nature.com/ bkechu).

We found that the proportion of women commissioned to write Nature News \& Views articles was much lower than the proportion of women scientists overall: female authorship was $17.3 \%$ for the biological and chemical sciences, $8.1 \%$ for physical sciences and 3.8\% for Earth and environmental sciences, with the proportion of women authors of Perspectives in Science being slightly larger. However, the pool of women scientists in these disciplines was significantly higher than the proportion of female authorship at 32\%, 16\% and $20 \%$, respectively.

It should be pointed out that a large proportion of invited News \& Views authors are full professors, and the percentage of full professors who are women is lower than that for all scientists. Also, the proportion of women full professors is smaller in the European Union than in the United States. However, the present proportion of women authors of News \& Views and of Perspectives is very low, and we believe that it is still fair to conclude that fewer women than men are offered the career boost of invitation-only authorship in each of the two leading science journals.

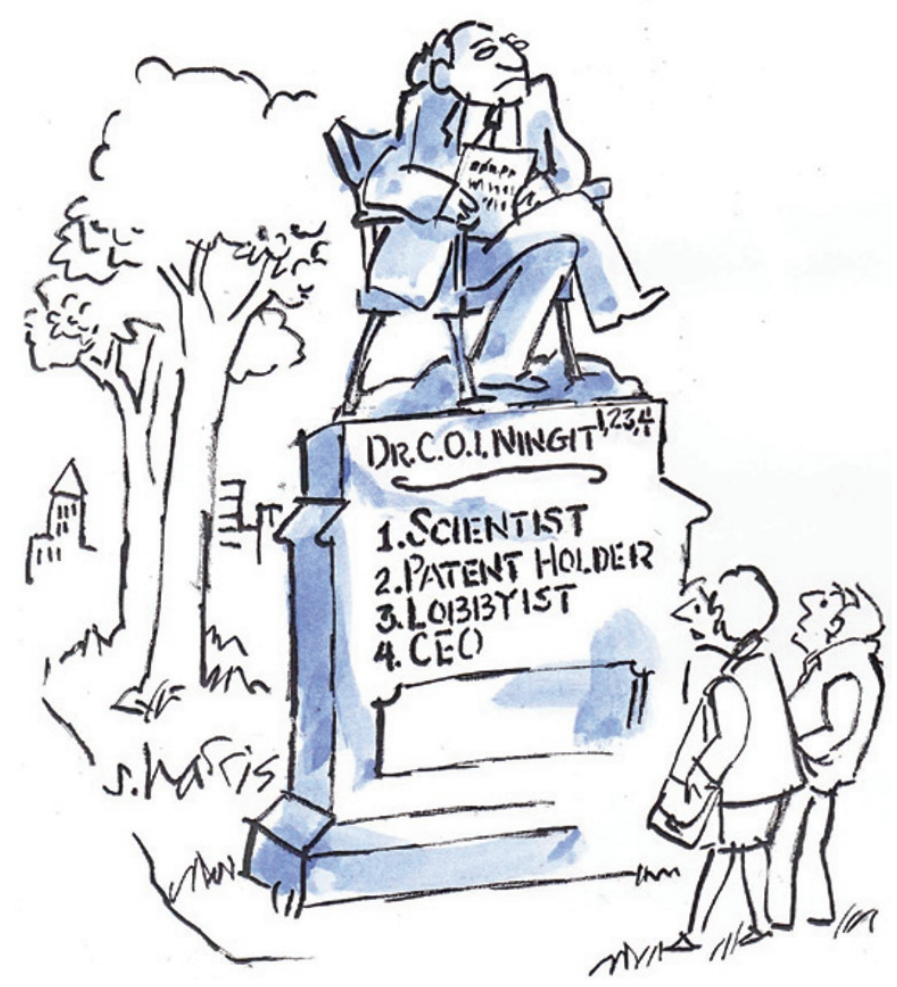

In response to earlier criticism, Nature increased the proportion of women authors in its Insight section (D. Conley Nature 438, $1078 ; 2005)$. It is time to extend gender parity for commissioned writers across Nature and Science. Daniel Conley, Johanna Stadmark Lund University, Sweden.daniel.conley@geol.lu.se

\section{Competing interests: expanding rapidly}

It is biased reports, not "the taint of scandal", that are the real danger in scientific research (Nature 488, 5; 2012). Without full disclosure of conflicts of interest (COI), universities and journals cannot begin to deal with the problem - but a disclosed conflict is still a conflict.

Declarations of conflicting interests shift to the reader the responsibility that should be borne by the editors to detect whether reported findings could have been warped by bias. The reader, even when forewarned, is not always in a position to judge the extent to which the financial interest of an author or investigator has consciously or unconsciously influenced their assessment of the evidence.

Our courts deal with this problem more effectively. For example, a judge or juror with a financial interest in a case must not only disclose it, but also withdraw from the proceedings.

As conflicts of interest become more common, there is a risk that the proliferation of footnotes disclosing them will desensitize our apprehension of bias. Arleen B. Rifkind Weill Cornell Medical College, New York, USA. arifkind@med.cornell.edu

\section{Competing interests: judged in perpetuity}

Full disclosure of competing interests is necessary so that readers can judge the conduct, validity, merit and reporting of research (Nature 488, 5; 2012). But this needs to go beyond simply revealing financial connections, because conflict with non-financial interests can sometimes be more serious
(D. F. Horrobin Br. Med. J. 318, 466; 1999).

Arguably, anyone who writes in a scientific journal may be biased in some way or another. Authors who are tempted not to disclose competing interests need to remember that readers continue to act as 'peer reviewers' after publication.

Thomas C. Erren University Hospital of Cologne; University of Cologne, Germany.

tim.erren@uni-koeln.de

\section{Biomass energy holds big promise}

Australia's government strongly supports the production of energy from renewable sources. But it is not yet tapping into biomass - the country's most costcompetitive renewable source.

Australia could generate at least 50 million tonnes of economically available biomass every year, with potentially millions more coming from sustainable forest management and from decomposed waste. With the help of mature bioenergy technologies already in use in other countries, this could provide more than $20 \%$ of the country's primary energy for heat, electricity and transportation. Modern biomassfuelled plants have a fuel-toenergy conversion efficiency of more than $85 \%$, comparing favourably with Australia's present coal-fired condensing plants and gas-fired turbine systems.

We should follow the lead of countries such as Austria, the land area of which is roughly $1 \%$ of Australia's (much of it comprising urban regions and alpine reserves). Austria produces more than 20 million tonnes of biomass as wastes and residues for energy production. In 2009, this constituted more than half of the $30 \%$ of primary energy that came from renewable sources.

Using sustainably produced biomass instead of fossil fuels can cut greenhouse-gas emissions, depending on effective use of 